\title{
Teaching and Learning - A Complementary Study on Effective Teaching and Learning
}

\author{
Syed Ali Abbas ${ }^{1}$ \\ ${ }^{1}$ Institute of Business \& Management, UET Lahore, Pakistan \\ Correspondence: Syed Ali Abbas, Institute of Business \& Management, UET Lahore, Pakistan. E-mail: \\ aabbas724@gmail.com
}

Received: August 11, 2016

Accepted: August 25, 2016

Online Published: September 27, 2016

doi:10.20849/aes.v1i2.73

URL: http://dx.doi.org/10.20849/aes.v1i2.73

\begin{abstract}
This study aims to recon the importance of effective teaching and the means to bring about the best out of teaching in contrast to learning and its outcome. The literature reviewed in the study has been arranged and segmented to identify the characteristics of effective learning and factors that may affect quality teaching. The newness in the study is the suggestions and conclusive part which is being derived from the prior studies. The study has some potential areas to explore which open new horizons for improving class room teaching which can also be taken as lead to future research. The thoughts and views of the author add a lot to originality of the study as they mandate a foundation that effective teaching and quality learning work in connection with each other, however student's effort is another must to be considered which encompass student's responsibility.
\end{abstract}

Keywords: teaching, learning, effective teaching, outcome based education

\section{Introduction}

\subsection{Learning and Its Importance}

Reaching moon may not sound as astonishing now, climbing mountains are no more a tougher job, drones cultivating fields is not considered a miracle whereas replacing robotics for soldiers won't be a day dream even. How has it happened, what has made all these fascinations a reality, what has brought human to be on what he is today is the sheer curiosity to learn and learn only? Therefore, the importance of learning can't be neglected from any sphere of life. Be it a family's ethical gathering, a scientific laboratory, a place of political agendas or a sports competition it's the ability to learn and implement which actually makes a difference, and once the learning is accomplished then execution and reaching conclusion becomes easier, but the first step is learning. Academically the initial phase of human learning starts from schools, these days preschools in which student is set to direction or pattern of learning. This learning in compatibility and in total alignment with his/ her brain reaches the next level as he/ she passes various level of education I.e. Primary school, secondary school, college and finally higher education (university). So basically what learning is all about as Ileris (2002) states it's actually a change in human attitude and behavior which is outcome of the learning. And as technological advancements and human's life style keep on changing, the importance of learning can't be neglected whether it's about the human of Stone Age or the human aiming to live in space.

\subsection{Problems in Modern Day Learning}

Although the importance of learning has been discussed briefly in previous part, yet the problems occurring in the learning process is manifold. The way human is advancing learning procedures, exactly at the same way it has to counter the issues in learning to get the best out of learning. Therefore addressing the problems in learning, especially in context to class room education is merely important, because class room learning plays a pivot role in human development (Barton, 2002). If that was not the case then all economic development and GDP growth must not have been linked to literacy rate of nations. Therefore, to meet the modern era demand of learning and to rectify the problems occurred in learning, no one but better understanding among student and teacher could best resolve all the discrepancies in effective learning. That leads to the objectives of this study which is to analyze

\subsection{Objectives of the Study}

\section{$>$ Characteristics of Effective Learning}




\section{$>$ Characteristics of Effective Teaching}

$>$ Factors of Effective Teaching

$>$ Characteristics of Effective Assessments

\section{Characteristics of Effective Learning}

\subsection{Student Right \& Responsibility}

A student must be aware of the fact that it's one of his prime duties and responsibility to be ready for learning. $\mathrm{He} /$ she must not be making excuses and taking learning as an easy task for granted.

\subsection{Understanding the Importance of Learning}

A student should have clear understanding of learning and its benefits. He/ she should consider learning as an instrument of change thus meeting all his/ her futuristic demands.

\subsection{Knowledge Creation and Integration}

An important characteristic of effective learning is experienced if it enables the students to think creatively (David, 1998). As creativity is the only competitive advantage that last long, so in the event if learning enables the student to initiate novel ideas and allow them to integrate with real world setting, the learning is got to be effective.

\subsection{Sense of Challenge and Support}

Testing oneself is not an easy task to do as accepting challenges mainly result in success, therefore, if learning has resulted in making student challenging to all new tasks and the acquired knowledge supports him/ her in justifying the challenge, one must admit that his/ her learning methodology has been surely effective.

\subsection{Students'Skills}

Reading, learning and writing are some of the common skills required for effective academic success (Rosenfeld, 2001). If learning process acquires students to capitalize on all these skills or in other words these set of skills are being used at its optimum level, the learning has surely been effective.

\subsection{Students and Assessments}

No procedure is worthy enough unless its outcome is not known. Exactly the way an effective learning can be assured if students have access or knowledge about the assessment criteria (Guskey, 1997). It's pretty hard to digest the fact that in most $3^{\text {rd }}$ world countries the students, especially at the school and even college are unaware of the passing criteria, which results in lack of interest in the learning. So, if the students are aware of the grading and passing criteria their learning would surely be interesting and different than what it could have been the other way.

\subsection{Diversity in Learning and Its Acceptance}

Often students find it tough to link their learning methodology with trainer/ teacher thus losing interest in learning, and once the interest is lost the efficacy of learning can be questioned (Jaques, 2000). Hence, it is recommended that teacher should be open in accepting and understanding learning approaches being practiced by the students with definite correction, wherever required.

\subsection{Learning in Line with Social Necessities}

Learning couldn't be an outcome based unless incorporate the element of society in it, Social problems, social issues and routine examples in learning make it a perfect mix for quality learning (Joseph et al, 2015).

\subsection{Students' Value and Opinion}

If student can relate its values and integrate its personal opinion in learning process, it means the learning has got to be fruitful.

\subsection{Meta-cognitive Learning}

The most important element if effective learning is its ability to identify new problems and then rectifying its solutions and means to overcome it. This all make learning a pleasant experience thus making learning an interesting and outcome based.

\section{Characteristics of Effective Teaching}

As previous portion has stressed on effective learning, this part will describe the mentors/ teachers' and trainers' role as how they deliver, communicate and transfer their knowledge to students as their lecture delivery plays a 
main part in making learning an effective experience. The characteristics which are considered for effective teaching include:

\subsection{Teacher's Love to His/ Her Subject}

It is believed that loving the job or in simple words loving what you do makes your job a happy workplace. Similarly, a teacher should actually love or has great interest in what he/she teaches. His/ her interest in the subject will open new horizons of learning for him/ her and the students. It will be dismal sight to witness a teacher teaching a subject in which he/ she actually is not interested and lacks command.

\subsection{Interesting \& Stimulating Material}

Teaching is not every one's job as it requires someone to be a man of many talents. A good teacher is not only rich in experience or academics but it's actually the interesting course and study material which does it for a successful class. Interesting resources, real time examples and notes which a student can relate with him/ her altogether pave way for effective teaching.

\subsection{Active Learning}

Gone are the ages when passive learning was practiced and students were meant to cram what they used to listen from teacher exactly (McDonald, 2015). It's an era of android generation in which student has sharpened with new set of skills and has ready access to updated knowledge with just one click away, therefore it's the active learning, a two way learning that is required to make teaching as a quality oriented job.

\subsection{Clear Communication}

Simplicity is better. The simpler the terminology used in the class, the easier will be for students to grab the concepts. A teacher should avoid using complex words just for the sake to impress the students. It may harm even best of the lectures.

\subsection{Paying Respect}

As discussed above that learning is two way these days, similarly respect is a two way process. It may further be implicated from Hofstead cultural dimensions that in countries where power distance is high, the element of respect is considered to be one way as respect is shifted to higher level of hierarchies (Hofstede, 2001). That's why teacher should understand that student, though has come to class for learning yet he/she expects and deserves respect. Being teacher doesn't allow someone to be a cruel person but a helpful resource instead.

\subsection{Agility and Adaptability}

Agility and adaptability are must in work place. A teacher should aware of the fact that fast paced technological advancements have revolutionized the learning methodologies therefore teacher should keep him/herself ready for learning new skills, news methods of technology in education and knowledge updating as per new theories and research, so that he may recognize himself as a modern day teacher of modern students.

\subsection{Valid and Unbiased Assessments}

The assessment criteria should be made clear to students in advance and be valid and unbiased (Stiggins, 2002). Student should have knowledge about grades and all criteria that should be justified and in line with the learning methodology in the class. Student at any point of assessment/ exam must not feel that he/ she has been overlooked or has experienced biasedness over some other student. In this way he may lose interest and teaching may not remain effective for him.

\section{Factors of Effective Teaching}

After discussing important characteristics, here are some of the factors that have influence on how teaching ought to be? These are as under:

\subsection{Clarity of Presentation}

The presentation material, presentation style, the content chosen and even the color scheme used in the presentation are some of the ingredients that may affect the lectures. So using a good blend of these factors can definitely affect teaching in a positive way.

\subsection{Educator's Enthusiasm}

If your class finds an enthusiastic, active and efficient teacher it will flow in the same pattern. In contrast if a teacher himself is slow in communicating or taking actions, delays in response and organizes class at snail's pace, it can transform the same in listeners which may affect the quality of delivery. 


\subsection{Lecture \& Variety of Activities}

Just coming straight away in the class and starting lecture in the same fashion may initiate the feeling of repetition in class (Alam, 2011), that's why it is desirable for teacher to have various teaching methodologies to make subject interesting and amusing so that students keep waiting for something new, every time they chip in class. Things like case studies, video based lecturers, some management games or computer aided online tests/ surfing may surely increase the lecture quality at highest notes.

\subsection{Attitude}

As quoted by Zig Ziglar that "If you don't see yourself as a winner then you can't perform as a winner", a positive attitude, attitude like a leader and attitude like a captain of the ship is everything what counts the most in lecturer. A teacher who needs to lead various set of people representing different families and various economical background at same page in same class is not a child's play, therefore his/ her attitude is the first thing that is counted and rated by the students. A never giving up attitude, a winning and high spirited attitude, and an attitude of a leader knowing s/he can motivate the entire class can take the class to next level of success and learning.

\subsection{Student Motivation and Recognition}

Recognizing students' abilities and performance in the class may not only ensure him to perform well in next sessions but may also provoke the under performers. Class should be aware of the fact that performers will be recognized, awarded and rewarded by the resource person (Hastings, 2012). Even a pat at the shoulder admiring student's effort would work wonder. Along with this, it is equally important for teacher to push up the non-performers, backbenchers in the class and to motivate them to become like his/ her participating fellows in the class. In this regard, the importance of class participation and assessment based on class participation can prove out to be very handy.

\section{Characteristics of Effective Assessment}

After discussing the important constructs of learning in detail, now is the time to overview the characteristics of effective assessments that ultimately lead to effective learning. These include

$>$ Assessment should actually reflect student efforts and hard work and is then justified by marks (Kifer, 2001).

$>$ Periodic assessments should be made during the course and student should be informed about his/ her ongoing performance as how can he change or amend it in terms of positive development (Bloom et al, 1981).

$>$ There must not be only traditional approach of assessing students in terms of final exam or quiz. Students can be analyzed on the basis of class participation, project work and involvement in course work.

$>$ Students can be involved in designing assessment methods and can themselves set the targets to accomplish. This will originate sense of responsibility and belonging in the students.

$>$ Assessment criteria should be made into practice which are clear and must not result in rising stress upon the students. As the purpose of assessment is to judge the students to boost their creativity, it's not about stressing them all the time.

$>$ Model answers to questions should be developed in advance and must be presented to students beforehand, so that they may have an idea about teacher expectation's as what and how to answer.

$>$ A uniformity and consistency in assessment criteria is mandatory so that all the students whether internal or external can be judged at same criteria.

\section{Conclusion}

Modern day learning is very demanding as it entails the students to be ready to meet new challenges at a pace like never before. Therefore to actually realize the essence of learning one has to understand the characteristics of learning that demands real change in entire set of habits of a student. To bring about this change not only understanding the characteristics of learning is important but how effective teaching can make a difference, is actually the need of the hour. However, it is important to stress the fact that since learning criteria are different nowadays exactly the way it is mandatory for a modern day teacher to update him/ her I.e. both mentally and knowledge wise as well. Also, the teacher has to act as more like a resource person on whom student may depend. From effective communication to motivating students, a teacher must have it all what this new student expects from him. The conclusion doesn't end here as the last part is effective assessment. Right from Learning 
to its characteristics and moving on to factors responsible for effective teaching, the significance of assessment criteria must not be put aside. The students should not only be assessed in unconventional ways as discussed in previous parts but also be aware of the ways they are being evaluated. In a nutshell, it's actually about active learning encompassing two way communications on the lines of quality, clarity and convenience.

If this all can be practiced then the real meaning of learning can actually be justified which is nothing but a change in human behavior (Illeris, 20).

\section{References}

Barton, P. E. (2002). Staying on course in education reform. Princeton, NJ: Statistics \& Research Division, Policy Information Center, Educational Testing Service.

Bloom, B. S., Madaus, G. F., \& Hastings, J. T. (1981). Evaluation to improve learning. New York: McGraw-Hill.

David, G. (1998). Knowledge, Creativity and Innovation. Journal of Knowledge Management, 2(1), 5-13.

Guskey, T. R. (1997). Implementing mastery learning (2nd ed.). Belmont, CA: Wadsworth.

Hastings, C. (2012). Teacher Motivation: The Next Step in L2 Motivation Research. TNTESOL Journal .

Hofstede, Geert H. (2001). Culture's consequences: Comparing values, behaviours, institutions and organisations across nations (2nd ed.). Thousand Oaks, California: Sage.

Illeris, K. (2002) The Three Dimensions of Learning: Contemporary Learning Theory in the Tension Field between the Cognitive, the Emotional and the Social. Leicester, UK: NIACE.

Jacques, R. (2000). Theorising knowledge as work: the need for a 'knowledge theory of value. In C. Prichard et al. (Eds.), Managing Knowledge. London: Macmillan.

Joseph E. Stiglitz, Bruce C. Greenwald, \& Philippe Aghion, K. J. (2015). Creating a Learning Society. Columbia University Press.

Kifer, E. (2001). Large-scale assessment: Dimensions, dilemmas, and policies. Thousand Oaks, CA: Corwin Press.

McDonald, I. (2015, July). Stabroek News. Retrieved from Cramming is not education. Retrieved from http://www.stabroeknews.com/2015/features/07/12/cramming-is-not-education/

Michael Rosenfeld, S. L. (2001). The Reading, Writing, Speaking, and Listening Tasks are Important for Academic Success at the Undergraduate and Graduate Levels. New Jersey: Princeton.

Muhammad Tayyab Alam, S. F. (2011). Factors Affecting Teachers Motivation. International Journal of Business and Social Science.

Stiggins, R. J. (2002). Assessment crisis: The absence of assessment for learning. Phi Delta Kappan, 83(10), $758-765$.

\section{Copyrights}

Copyright for this article is retained by the author(s), with first publication rights granted to the journal.

This is an open-access article distributed under the terms and conditions of the Creative Commons Attribution license (http://creativecommons.org/licenses/by/4.0/). 